\title{
Materialidades Discursivas de Mulheres Negras na Computação
}

\author{
Mory Márcia de Oliveira Lobo', Karen da Silva Figueiredo Medeiros \\ Ribeiro $^{12}$, Cristiano Maciel $^{12}$ \\ Programa de Pós-Graduação em Educação, Instituto de Educação - Universidade \\ Federal do Mato Grosso (UFMT), Cuiabá, Mato Grosso, Brasil ${ }^{1}$ \\ Instituto de Computação - Universidade Federal do Mato Grosso (UFMT), Cuiabá, \\ Mato Grosso, Brasil ${ }^{2}$ \\ moryprofessora@hotmail.com, karen@ic.ufmt.br, cmaciel@ufmt.br
}

\begin{abstract}
This paper aims to realize a speech analysis of statements published in electronic newspapers from two black women, who are protagonists in Computer Science. The methodology adopted was the French Speech Analysis by Pêcheux, in order to identify ideological circumstances of the hegemonic forces on the history of fight against the sexism and racism in the area of Computing. The starting point is the imaginary body projected in the professional field, which demands the confrontation of the mechanisms that are fragmenting the identities of race and gender, by a social excluding logic.
\end{abstract}

Resumo. $O$ artigo em voga busca analisar enunciados discursivos declarados por duas protagonistas negras da computação, em matérias de jornais eletrônicos. Para nortear as inferências a partir da interpretação utilizar-se-á a Análise de Discurso Francesa trabalhada por Pêcheux, visando identificar circunstâncias ideológicas de forças hegemônicas sobre o histórico de luta contra o sexismo e racismo na profissão, tendo como ponto de partida o corpo imagético projetado em um conjunto de contextos que passa pela área profissional e que exige enfrentamento dos mecanismos que fragmentam as identidades de gênero e racial movimentada em uma lógica excludente.

\section{Introdução}

A inserção de mulheres negras no campo da Computação nos remete a pensarmos em um cenário, por via ocupado por homens, e no percurso para essa inserção, movimentada por fatores de múltiplas dimensões. Este trabalho pretende identificar neste percurso de enfrentamento e resistência, traços expressivos da luta da mulher negra por espaços de poder, que são incorporados ao percurso, e em como a mulher negra se mantem no contexto de um sistema que não foi construído e pensado para a mulher enquanto empreendedora e, muito menos, para a mulher negra.

De acordo com o Centro de Inovação e Talento, em matéria [Da Hora 2019], $77 \%$ das mulheres negras em empresas de alta tecnologia afirmam que precisam provar sua competência mais do que seus pares. Segundo relatório da PretaLAB (2018), nos Estados Unidos, apenas $2 \%$ da força de trabalho de ciência e engenharia é de mulheres negras. Já no Brasil, não existem dados. Para transformar esse cenário, é fundamental pensar na democratização do acesso ao ensino em todos os níveis e aos processos de produção científica e tecnológica para mulheres de todas as raças e etnias.

Neste sentido, este artigo analisa enunciados discursivos declarados por duas 
protagonistas negras da Computação, provenientes de matérias de jornais eletrônicos. Estas mulheres são de países e realidades distintas: Annie Easley (estadunidense) e Flávia Roberta Silva (brasileira) e foram escolhidas para análise por serem mulheres negras de expressivas materialidades discursivas no ambiente profissional. Para nortear as inferências a partir da interpretação, utilizar-se-á a Análise de Discurso Francesa, trabalhada por Pêcheux (1995), identificando circunstâncias ideológicas de forças hegemônicas sobre o histórico de luta contra o sexismo e racismo na profissão tecnológica, considerando a trajetória, contexto e país de residência dessas mulheres.

A partir desta Introdução, este artigo se organiza da seguinte forma: a seção 2 discute perspectivas teóricas sobre as relações raciais, a mulher negra e profissão; a seção 3 apresenta a metodologia deste trabalho, incluindo a Análise de Discurso dos enunciados das entrevistas e, a seção 4, as considerações finais deste trabalho.

\section{Perspectivas teóricas}

Pensar sobre as relações raciais no Brasil torna-se uma tarefa complexa, pois a homens e mulheres de pele negra foi alvitrada uma imagem inferiorizada pelo processo de escravidão, que durou aproximadamente 358 anos (1530-1888). Assim, construiu-se na pessoa negra toda uma projeção de incapacidade intelectual, e consequentemente social, que a faz ser moldada e dirigida pela supremacia branca, utilizando como ponto estratégico o desejo de comportar-se como branco para obter capacidade intelectual como uma indução de conduta, o que caracterizaria como o mesmo que governar o pensamento das pessoas e sua subjetividade [Fanon 2008].

Schwarcz (1993) enfatiza que, da teoria darwinista, nasceram afirmações deterministas que sedimentaram a crença no biológico como pressuposto de inteligência, imprimindo neste componente biológico características físicas e morais. Esse pensamento também proporcionou uma leitura de mundo baseada na divisão de raças como uma divisão da cultura, servindo como base para princípios políticos de submissão aos que seriam considerados inferiores por critérios raciais.

Skidmore (1976) apresenta em seus estudos as realidades das relações raciais depois da abolição no Brasil, mostrando como o prestígio científico fortaleceu o pensamento racial em dois vetores: determinismo geográfico e determinismo racial. Nesta linha de pensamento, os países tropicais são inferiores e menos produtivos e os países glaciais ou polares, superiores e mais produtivos. Estas teorias foram validadas como científicas na época, e sobre elas se desenvolveu grande parte do pensamento da sociedade brasileira. O determinismo racial, advindo do darwinismo, teve sua base na miscigenação de raças, pois acreditava-se que nem mesmo um processo de evolução social levaria à transmissão de características morais adquiridas. Dentro desta concepção, as raças eram vistas como produtos finais, não poderiam ser "melhoradas" ou "aperfeiçoadas", sendo imutáveis por natureza. Por isso, o cruzamento racial era visto como um erro, que levaria à degeneração social [Skidmore 1976].

Também relacionado a este contexto, indicadores apontam que as mulheres construíram e constroem parte expressiva da força de trabalho, responsável por um número considerável do lucro capital de seus países de habitação [Marcondes et al. 2013]. No entanto, assim contradizem os papéis hierárquicos sociais a que lhes foram impostos por ideologias por consequência própria do seu histórico social nas relações de poder. Estudos e pesquisas voltadas para a mulher negra tem se fortalecido na intencionalidade de deslegitimar, desmistificar e desmontar formas de poder e contradizer afirmações pseudocientíficas relacionadas a estas mulheres [Davis 2016]. 
Constata-se que nas publicações em periódicos, no acervo de dissertações e teses encontradas no Catálogo da CAPES ${ }^{1}$, e nos grupos de trabalhos (GTs) da Associação Nacional de Pós-Graduação e Pesquisa em Educação (Anped), entre outros, que o tema mulheres negras na Computação ainda é discutido em número inexpressivo. No Google Trends $^{2}$ sequer há dados sobre mulheres negras em português ou em inglês na computação e tecnologias, bem como poucos registros para mulheres em geral.

No Brasil, um dossiê foi produzido pelo Instituto de Pesquisa Econômica Aplicada (IPEA) [Marcondes et al. 2013] para discutir a mulher negra e suas condições de vida. Neste dossiê, um fenômeno importante aparece na discussão sobre desigualdade de gênero, demonstrando um processo de interação sobre esse comportamento em dois eixos: subordinação na construção de situações de exclusão e opressão culminando no conceito de interseccionalidade ${ }^{3}$.

Nas teorias sobre mulheres, raça e classe trabalhada pela estadunidense Angela Davis (2016) são desnudadas a opressão, dominação e a discriminação. Davis, revoluciona o estado americano com seu livro "Mulheres Raça e Classe" no qual, não trata somente a opressão sobre a mulher negra, mas também levanta um grande questionamento social e subjetivo sobre a imagem que foi construída sobre ela e contra ela, na medida em que, ao longo do tempo, foi construída uma desumanização imagética, social e subjetiva sobre a mulher negra.

Davis [2016], contextualiza, a partir do processo escravagista, a luta das mulheres de cor estadunidenses para desconstruir a imagem desumanizada, trazendo nesse histórico os combates que tratavam contra seus senhores de escravos no fluxo das tentativas de abolição. Tal histórico de uma luta advinda do povo não é encontrado na dimensão brasileira. No Brasil, a formação é vertical a partir da coroa portuguesa.

Esse movimento de desconstrução imagética da mulher negra, possivelmente, consolidou-se a partir da revolução tecnológica, em que as questões raciais ganharam visibilidade nos meios de comunicação, alavancando o reconhecimento e a valorização social em setores importantes como: o meio artístico, o trabalho, o esporte, a política, as universidades e, também, por meio das ações afirmativas.

Estudos brasileiros como de Matos et al. [2016] e Lobo, Figueiredo e Maciel [2018], trazem a discussão sobre a inserção de mulheres negras na pós-graduação e nas tecnologias, respectivamente, apontando desafios profissionais; trajetórias de sucesso, apoio e reconhecimento de mulheres negras em rede; o uso de tecnologias como forma de resistência; e ações, que permitem fortalecer e sedimentar outros vieses de pesquisas sobre gênero e diversidade.

Por este motivo, analisar discursos subjetivos da mulher negra, consumidora e produtora de tecnologias, na intencionalidade de identificar contextos e demandas em que estes discursos estão inseridos, requer uma análise sofisticada sobre os espaços que foram dados a estas mulheres, na medida em que pesquisas apontam a mulher negra brasileira em posição de vulnerabilidade imposta na pirâmide social [Geledés,2015] ${ }^{4}$, sem poder de ascensão por consequência de um contexto histórico em que pessoas com a cor de pele preta foram consideradas inferiores aos da pele branca [Munanga 2015].

\footnotetext{
${ }^{1}$ CAPES: Coordenação de Aperfeiçoamento de Pessoal de Nível Superior https://catalogodeteses.capes.gov.br/catalogo-teses/\#!/

2 Em pesquisa realizada pelos autores pelos termos em março de 2019.

${ }^{3}$ São dois ou mais fatores de subornização heteronormativos (grifos dos autores).

${ }^{4}$ https://www.geledes.org.br/o-movimento-da-mulher-negra-brasileira-historia-tendencia-e-dilemas-contemporaneos/
} 


\section{Materialidades discursivas de Mulheres Negras no percurso profissional}

$\mathrm{Na}$ estrutura metodológica deste trabalho, empreende-se uma análise discursiva de duas mulheres negras atuantes do campo da Computação e tecnologias, a estadunidense Annie Easley e a brasileira Flávia Roberta Silva, por serem referências em suas áreas de atuação, dando destaque à luta emancipadora da mulher negra no campo profissional.

Os enunciados coletados e destacados neste trabalho passam pelo roteiro histórico e imagético reproduzido pela mídia. A interpretação dos dados foi realizada pela Análise de Discurso no modelo francês, que tem como base de coleta os elementos: formação ideológica, histórico, contexto, sujeito, sentido, memória, ethos, concepções de produção e formação discursiva. Tais elementos são analisados em conjunto.

Assim, os dados são analisados pela perspectiva qualitativa e descritiva, por meio de uma estruturação teórica atrelada a uma abordagem psicanalítica, para assim compreender o sintagma, que consiste em analisar e interpretar efetivamente os enunciados. Esta modalidade de pesquisa advinda da escola francesa tem como seu principal fundador Michel Pêcheux. Conforme Pêcheux (1995), é importante observar que as palavras mudam de sentido segundo as posições sustentadas e, por isso, a materialidade das falas no cenário se funde com acontecimentos históricos ao serem sustentadas também pelos veículos de comunicação, sofrendo constantes mutações.

$\mathrm{O}$ autor afirma que, na metodologia de Análise de Discurso, a observação da classe social e a interpelação cultural sócio-histórica dos atores falantes são elementos determinantes dos sentidos, na medida em que, analisadas as materialidades que norteiam e fundamentam as ações e comportamentos mais comuns, explicam de que forma o pensamento humano é executado e conduzido por ideologias.

Vale ressaltar que, neste contexto este trabalho parte de um olhar contemporâneo para o histórico de luta sexista e racista na área da Computação, tendo em vista a relevância da pesquisa científica no fortalecimento de políticas de acesso e na desconstrução de ideologias excludentes para a mulher negra.

\subsection{Análise de dados 1: Annie Easley}

Nesta primeira seção, analisar-se-á as materialidades discursivas da estadunidense Annie Easley ${ }^{5}$, utilizando do seu histórico biográfico como competente inicial da análise atrelada aos elementos verbalizados nas entrevistas. Cientista na área da Matemática, da NASA National Aeronautics and Space administration e membra do Comitê Consultivo Nacional para a Aeronáutica (National Advisory Committee for Aeronautics - NACA), Annie desenvolveu o software do foguete superior de alta energia Centaur.

Annie Easley construiu um sólido caminho de luta social pela causa racial e sexista. Annie nasceu em 1933, no estado do Alabama (um dos palcos da segregação racial norte-americana). Em seus relatos, ela relaciona sua vontade de vencer pelo incentivo dos pais. Sua primeira formação foi em Farmácia, e em 1977, Annie tornou-se Bacharel em Matemática. Em 1955, ela ingressou na NASA, a priori para a tarefa de realizar cálculos e, posteriormente para atuação direta com codificação. De acordo com dados do portal histórico da NASA, o Johnson Space Center (JSC 20016), foi com o apoio da agência que ela desenvolveu e implementou o software que analisou tecnologias solares e energias eólicas alternativas para veículos elétricos, e que realizou estudos sobre a vida e o uso de baterias de armazenamento.

\footnotetext{
${ }^{5}$ https://www.nasa.gov/feature/annie-easley-computer-scientist

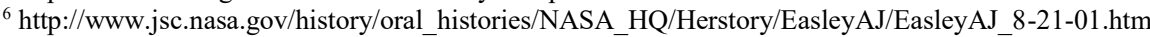


Em uma entrevista ao Projeto Centauro, com Sandra Johnson do JSC em 21 de agosto de $2001^{7}$, Annie lembrou a triste experiência de discriminação e racismo que enfrentou no ambiente de trabalho. No seu relato, ela destacou que foi literalmente cortada de uma foto de trabalho quando esta foi colocada em exibição para o público. $\mathrm{Na}$ foto havia seis pessoas e ela era a única membra de minoria da equipe. A esse fato, Annie acrescenta:

"Nada jamais foi dado às minorias ou às mulheres. Foi necessário lutar para conseguir oportunidades iguais, e continuamos lutando hoje em dia." - Annie Easley em entrevista para a JSC em 21/08/2001.

De acordo com a Historiadora Margareth Rago (1985), a década de 1950, época em que Annie Easley entra para o mercado de trabalho na NASA, foi de grandes tensões e mudanças mundiais, pois avanços na ciência, tecnologia e meios de comunicação, como o início das transmissões de $\mathrm{TV}$, foram fio condutor para conflitos de grande expressividade social, como a Guerra Fria. Tais acontecimentos permitiram o estabelecimento de teorias pseudocientíficas, costumes e posicionamentos sexistas e racistas, entre outros. Desta forma, o discurso empreendido por Annie no enunciado selecionado, denota um cenário de rompimento, ao reconhecer o percurso das minorias sem direitos e que sua formação ideológica se dá a partir do seu histórico sexista e racial, no qual decidiu enfrentar pela área profissional.

No enunciado, Annie se coloca no "lugar" de minoria em direitos e destaca a identidade dessa luta, reconhecendo que ela é interminável no sentido de combater a discriminação como forma de emancipação. No trecho "Foi necessário lutar para conseguir oportunidades iguais" há um jogo de imagens desse percurso trilhado por ela, em que as representações imaginárias se tornam elementos orientadores na forma representativa de ver a si e ao outro, em um posicionamento ideológico de resistência dentro de uma estrutura de poder liderada por homens e brancos.

Para o autor francês Frantz Fanon (1968), a despersonalização racial e a negação do reconhecimento da pessoa de cor tiveram um custo psicológico ao negro. Hooks (2015) reitera que para a mulher negra esse peso é ainda maior porque esse reconhecimento é negado pelo pensamento sexista e racial. Pêcheux (1995) intensifica o lugar social e as condições sociais que definem a produção dos discursos e esses lugares sociais assumidos influenciados pela formação ideológica que passa pelo "sentido" partindo do entendimento refletido determinante na forma de compor o discurso.

$\mathrm{O}$ percurso histórico de Annie Easley mostra-se determinante para a desconstrução da hegemonia branca e sexista, levando em consideração a época que marca o início de grandes mudanças sociais no mundo e, também, na forma como expressa o reconhecimento dessa luta. Casimiro (2005), denota a atenção para os suportes ideológicos, que chama de fenômenos mimese ${ }^{8}$, que influenciam a construção da identidade de mulheres moçambicanas, em que materialidades discursivas de cunho constrangedor permeavam a disputa por espaços de homens e mulheres na luta por emancipação feminina que somente ganhou força a partir da década de 1960.

Portanto, a luta por oportunidades iguais materializada no discurso de Annie potencializa seu percurso profissional na Computação ao relacionar a figura da mulher negra com o período histórico. Fica aparente a autoafirmação de relação pedagógica pela profissão, na qual contextualiza a história, desconstrói estereótipos e movimenta o

\footnotetext{
${ }^{7}$ http://www.jsc.nasa.gov/history/oral_histories/NASA_HQ/Herstory/EasleyAJ/EasleyAJ_8-21-01.htm

${ }^{8}$ Mimese: a origem do termo decorre desde o século IV a.c., e correspondia à "imitação", "representação", "indicação", "sugestão", "expressão", sempre referente à ideia de fazer ou criar algo que se assemelhe a outra coisa.
} 
início de um processo árduo de descolonizar pelo conhecimento e pela prática imagética.

\subsection{Análise de dados 2: Flávia Roberta Silva}

Nesta segunda sessão, são analisados dois enunciados da brasileira Flávia Roberta Silva ${ }^{9}$, incluindo componentes como o histórico biográfico para norteará o levantamento de dados, com comparativos do histórico dos países das analisadas. Formada em Ciência da Computação pela FATEC RJ e Mestra em Administração de Negócios pela Fundação Getúlio Vargas, há 22 anos Flávia trabalha na IBM gerenciando projetos internacionais. Flavia cita como pontos referenciais de sua profissão o pai, um homem muito inteligente e a avó que era da Marinha, como grandes incentivadores na profissão e na identidade racial. [Mulheres na Computação 2018]. ${ }^{10}$

Duas falas de Flávia (em entrevistas) foram selecionadas para a análise discursiva, buscando contextos do percurso de sua carreira e relacionando a sua luta, tendo em vista o percurso da formação do pensamento racial no Brasil. Levam-se em consideração as diferenças do percurso de Annie Easley, nos Estados Unidos, apontados na primeira análise, por considerarmos diferentes as abordagens constitutivas destes percursos. De acordo com Nogueira (1996), ao mencionar o esquema de comparação entre estes dois países, os Estados Unidos têm um sistema universal que postulou o preconceito de origem $^{11}$, enquanto no Brasil, em decorrência das relações hierarquizadas, sedimentou-se um preconceito de marca $^{12}$.

Este sistema abrangente e classificatório no Brasil, precisamente fundamentado em condições ordenadas, é apontado por muitos cientistas sociais citados neste trabalho, como o expressivo motivo da crise identitária do afro-brasileiro que se autodeclara parda e às vezes, até branca em pesquisas, nos discursos e no comportamento relacional com a sociedade em geral [Gomes 2002]. Nogueira (2006) salienta que o preconceito de marca, como acontece no Brasil, é articulado por situações de desprezo declarado, por atitudes e discursos sedimentados culturalmente que excluem e impedem o discriminado de competir em igualdade pelo grupo discriminador, por causa do estereótipo inculcado em padrões de branquitude como: nariz afinado, olhos pequenos e lábios finos, entre outros padrões impostos como exemplo da beleza branca.

$\mathrm{Na}$ primeira entrevista selecionada, Flávia discorre ao $\mathrm{G} 1^{13}$ sobre negros e pardos que ocupam cargos de chefia no Brasil, trazendo para sua fala um misto de processos considerados racionais. No entanto, estes processos são advindos também de submissões inconscientes de natureza ideológicas, que se destacam na disputa de pensamentos e que determinam o lugar social que este sujeito ocupa como ser social. Para Mussalim (2001):

"[...] aquele que ocupa um lugar social e a partir dele enuncia, sempre inserido no processo histórico que Ihe permite determinadas inserções e não outras. (...) o sujeito não é livre para dizer o que quer, mas é levado, sem que tenha consciência disso, a ocupar seu lugar em determinada formação social e enunciar o que Ihe é possível a partir do lugar que ocupa".

\footnotetext{
${ }^{9} \mathrm{https}: / /$ www.linkedin.com/in/flavia-roberta-silva-7523b2b/

${ }^{10}$ Evento organizado pelo SAP Next-Gen e BWN. 2018 https://mulheresnacomputacao.com/2018/08/page/2/

${ }^{11}$ Preconceito de Origem: Manifesto e incontestável [...] quando basta a suposição de que um indivíduo descende de certo grupo étnico para que sofra as consequências do preconceito [Nogueira 2006].

${ }^{12}$ Preconceito de Marca: quando o preconceito de raça se exerce em relação aparência, isto é, quando toma por pretexto para as suas manifestações os traços físicos do indivíduo, a fisionomia, os gestos, o sotaque diz-se que é de marca [Nogueira 2006].

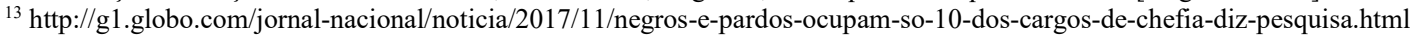


Neste sentido, nas mediações do discurso atreladas ao histórico da construção do pensamento racial no Brasil, que aparecem empreendidos na fala de Flávia no relato biográfico acima quando cita a referência da família, encontraremos o elemento orientador de sua produção, baseado na imagem de si mesma diante das condições em que atribui seu "lugar" de fala na questão racial e na luta sexista, pela forma como executa seu pensamento na segunda entrevista quando diz:

"Perdi noites de sono, comecei a tomar portas na cara. Mas conheci o mundo pela IBM e gerenciei projetos internacionais. Casei e engravidei. Em três meses, obtive certificações em tempo recorde, com planejamento e foco. Fiquei grávida de novo, mas isso me custou, pois tive depressão pós-parto no retorno. São altos e baixos que fazem parte da carreira de muitas pessoas. Tem momento de glória, mas tem muito rock and roll. E é assim que nos fortalecemos. Não temos ideia de onde podemos ir, imaginamos uma história e os caminhos vão mudando. É preciso centrar, parar e pensar" - Flávia Roberta Silva em entrevista para a Mulheres na Computação 2018.

Como recomendação, Flávia sugere que "as mulheres estejam sempre prontas $e$ invistam pesado no networking, pois ele faz a diferença.". É sensato considerar na análise de discurso o contexto evidente e a imagem comportamental que evidenciam os fatos relatados por Flávia no percurso histórico que sedimentou sua profissão. A representação que enuncia sua posição pelos índices formais: perdi, comecei, conheci, gerenciei, casei, engravidei são pontos reveladores sobre a subjetividade inferida pela qual a locução apresenta a marca da pessoa [Brandão 2004].

Neste sentido, as afirmações verbais presentes em sua fala posicionam o lugar constitutivo de sua subjetividade na sociedade, pela ação que ela julga desenvolvedora do seu protagonismo profissional pelo caminho trilhado, ao enfatizar e afirmar o mérito como aptidão. Considerando o histórico da formação do pensamento racial no Brasil por base na eugenia ${ }^{14}$, percebe-se nas linhas da formação discursiva de Flávia a ausência dessa reflexão no plano coletivo.

A essa questão, Pêcheux (1995) refere-se à formação discursiva de um tipo de esquecimento pelo qual o sujeito, interpelado por seu processo de formação ideológica, cria uma realidade discursiva ilusória. Tal esquecimento é uma zona inacessível ao sujeito, aparecendo precisamente, por essa razão, como o lugar constitutivo da subjetividade. Por esse esquecimento, o sujeito rejeita e apaga inconscientemente qualquer elemento que remeta ao exterior da sua formação discursiva. Nesse processo de apagamento, o sujeito tem a ilusão de que ele é o criador absoluto de seu discurso [Brandão 2004].

Fanon (1968) denominará esse percurso discursivo como dissonância cognitiva, pela qual o sujeito não se deixa influenciar por novas evidências, pois é protegido pela racionalização e pela negação dos fatos em um plano inconsciente. Isso significa, que na formação discursiva de Flávia permeada pelo contexto da formação racial no Brasil, o posicionamento assumido destaca-se mais pelas condições sociais que a mesma apresenta, do que pela posição discursiva no histórico racial que definem a forma de ver e representar o tema. $\mathrm{Na}$ análise de discurso, o sentido está relacionado às formas de interpretação do momento histórico [Mussalim 2001], portanto questiona-se: qual era o momento histórico racial de Flávia Roberta Silva na época da entrevista em 2018 ?

É possível que o segundo excerto discursivo de Flávia decodificado pelo

\footnotetext{
${ }^{14}$ A ideia da eugenia criada por Francis Galton em 1883, conhecida como a ciência da hereditariedade e marca a era moderna do pensamento racial. [...] eugenia é um movimento cientifico associado ao darwinismo e mendelismo social, é um programa social que privilegia o controle direto da reprodução humana, dos métodos indiretos de melhoramento humano pela reforma do meio ambiente [Stepan 2005].
} 
discurso, elementos, contexto e sentido responda ao que Pêcheux (1995) vai chamar de condições de produção, pelas quais os sujeitos não são representados como pessoas físicas e sim lugares sociais. Esse lugar aparece quando diz:

"Eu nunca me senti menor. Muitos negros ainda não enxergam as oportunidades. Até onde eu posso chegar? A ideia é fugir dos estereótipos e mostrar as possibilidades Flávia Roberta Silva em entrevista para o G1 em 2017.

Aqui o jogo de imagem determinante pelo pronome "eu" define não só as condições de produção, mas a imagem de si e do outro pela forma como as inferências se dão a partir do posicionamento ideológico. Partindo desse posicionamento a inferência apresenta-se condicionada tanto no histórico como na formação ideológica, quando a mesma afirma que o negro é que não enxerga as oportunidades.

O Brasil é um país cujo ideologia do branqueamento permeada pela falsa democracia racial ${ }^{15}$ ativa uma dimensão operacional das questões raciais pela qual um limbo epistemológico se coloca na limítrofe dessa discussão de modo a subordinar o efeito do sentido pelo esquema do esquecimento ou como diria Frantz Fanon pela dissonância cognitiva.

Vale ressaltar que o espaço dado a mulheres negras para o debate das condições femininas e luta pela emancipação profissional foram fruto de conquistas em que alterações epistemológicas fragilizaram estruturas sedimentadas de hegemonia masculina e branca, portanto adentrar nesse cenário com espírito de luta sexista e racial empreende luta social.

Neste caso, é sensato supor que essa luta levará esta mulher a buscar recursos internos e externos que potencializem não somente a entrada nesses ambientes, mas a permanência. Flávia, com vinte anos de IBM, retrata um pouco desse dinamismo ao verbalizar que: "a ideia de fugir dos estereótipos e mostrar as possibilidades".

$\mathrm{O}$ verbo fugir na ação traz o contexto e o sentido representados pela afirmação dos mecanismos utilizados pela mesma para compor sua luta relacionada ao desejo de romper com o sistema excludente e empreender sobre ele voz, dinamismo e capacidade intelectual até então colocado em vulnerabilidade pelo pensamento racista e sexista imposto socialmente.

Considerando que as ciências ligadas a computação foram construídas com a participação de mulheres e que o papel feminino foi de suma importância para a evolução da informática [Schiebinger 2001], destaca-se também essa construção nas relações sociais. Embora o cenário histórico apresente contradições, percebe-se toda uma conjuntura de resistência, ainda que inexpressiva, necessária às mulheres negras que enfrentam o desafio de sair da invisibilidade cientifica pela luta e enfretamento do sistema demonstrando capacidade e dinamismo em suas construções.

\section{Considerações Finais}

Considerando os resultados das materialidades discursivas encontradas na análise dos enunciados das entrevistas e as similaridades configuradas pelos discursos, foi possível inferir algumas questões. Após mensurar os dados e analisar as falas, alguns requisitos

\footnotetext{
${ }^{15}$ A ideologia do branqueamento refere-se à integração dos negros via assimilação dos valores brancos e teve como objetivo propagar que não existiam diferenças raciais no Brasil e que todos aqui vivem de forma harmoniosa, sem conflitos. A isto damos o nome de democracia racial. Essa linha de pensamento projeta uma nação branca que, através do processo de miscigenação, irá arrancar o negro da nação brasileira, supondo-se assim que a opressão racial acabaria com a raça negra pelo processo de branqueamento [Skidmore 1989].
} 
foram levantados para uma efetiva compreensão dos resultados em três pontos importantes:

- Marco referencial: o histórico das relações raciais nos países das analisadas e as consequências da colonização para o negro, enfatizando as mulheres negras e o percurso delas na profissão, como produtora de tecnologias.

- Classificação dos elementos: utiliza-se das falas verbalizadas para encontrar o fenômeno. A partir do sintagma, o primeiro fenômeno que aparece nos discursos analisados foi diferentes construções ideológicas na formação do pensamento racial entre Estados Unidos e Brasil, pelo histórico e apropriações trabalhadas por Fanon (2008), formando agrupamentos de sentidos que permearam todo o trabalho. Desta forma, as variantes comuns como: verbos e pronomes são utilizados para explicar as consequências dos processos de cunho racial e sexista diretamente ligados a subjetividade da mulher negra na sua relação coletiva, demonstrando como ocorreu a construção do pensamento racial.

- Inferências encontradas: no excerto de Annie Easley, encontramos o percurso histórico de uma mulher negra que produzia tecnologia no contexto de 1951, sendo a entrevista de 2001. Nela, há um posicionamento ideológico de pertencimento as massas de luta incorporadas no discurso, acoplada ao significado de sua trajetória profissional como uma cientista da NASA. Annie Easley ainda se vê como minorias em direitos porque seu discurso apresenta-se no plano coletivo imbuída de elementos de luta sexista e racista em que engloba outras mulheres que não conseguiram chegar onde ela chegou por um motivo social de relações de poder. Já no excerto de Flávia, encontramos o mesmo percurso histórico de luta em um contexto mais atual (2017/2018) em que a mulher já saíra da invisibilidade profissional em várias áreas de conhecimento. Porém, seu discurso apresenta outra dimensão de luta permeada pelo histórico da formação do pensamento racial no Brasil, pela qual essa construção social de relações de poder é isenta da responsabilidade da luta sexista e racista para um plano individual de luta. Ou seja, as oportunidades de ascensão social aparecem pelo discurso no campo meritocrático de aquisição de conhecimento e não sociológico de formas hegemônicas de poder.

Portanto, fica a observação do encontro do sujeito constituído de sua história de vida com seus objetos, pela qual este trabalho desenvolveu-se e que, associado à construção teórica, ganha significados importantes para reflexões no campo das relações interpessoais intrínsecas à realidade social, racial e sexista em tempos de grandes mudanças no cenário mundial e de extrema relevância para o debate racial e sexista no panorama brasileiro atual.

Os resultados encontrados neste trabalho revelam um discurso que desemboca às teorias raciais e a relevância de empreender estudos sobre raça e gênero como categorias que analisam essas dimensões, de formas mais sofisticadas e abrangentes, em áreas como a Computação. Desta maneira, pode-se compreender fenômenos que continuam alicerçando o sexismo e o racismo, as consequências psicoemocionais desses binarismos, assim como identificar os mecanismos utilizados para enfrentamento de tais questões. Em especial, a suposta inferioridade biológica e intelectual que sempre foi imputada à mulher e, de forma mais expressiva, à mulher negra, dentro de um contexto social e histórico que precisa de maior contundência de debate no campo da pesquisa.

\section{Referências}

Brandão, H. M. (2004) "Introdução à análise do discurso". 2a Edição revisada: Campinas, SP: Editora da UNICAMP. 
Casimiro, I. M. (2005) "Samora Machel e as relações de gênero". In: Estudos moçambicanos, n. 21, p. 55-84.

Da Hora, A. C. (2019). "Hacker antirracista: conheça a história de Ana Carolina da Hora", In: PERIFA CONNECTION, Carta Capital. Disponível em: www.cartacapital.com.br/blogs/perifaconnection/hacker-antirracista-conheca-ahistoria-de-ana-carolina-da-hora/

Davis, A. (2016) "Mulheres, raça e classe". Boitempo Editorial, 255 p.

Fanon, F. (1968) "Os Condenados da Terra”. Ed. Civilização Brasileira, Rio de Janeiro.

Fanon, F. (2008) "Pele negra, máscaras brancas". SciELO-EDUFBA, 194 p.

Geledés e Criola. (2016) "A Situação dos Direitos Humanos das Mulheres Negras no Brasil: Violências e Violações". Disponível em: https://www.geledes.org.br/wpcontent/uploads/2016/11/Dossie-Mulheres-Negras-PT-WEB3.pdf

Gomes, N. L. (2002) "Educação e identidade negra". In: Aletria: Revista de Estudos de Literatura, v. 9, p. 38-47.

Hooks, B. (2015) "Mulheres negras: Moldando a teoria Feminista.", In: Revista Brasileira de Ciência Política, nº16. Brasília, p.193-210.

Lobo, M. M.de O., Figueiredo, K. da s., Maciel, C. (2018). A Mobilização de Resistência das Mulheres Negras na Computação e Tecnologias. In $12^{\circ}$ Women in Information Technology (WIT 2018) (Vol. 12, No. 1/2018). SBC.

Marcondes, M. M. et al. (2013). "Dossiê mulheres negras: retrato das condições de vida das mulheres negras no Brasil”, IPEA - Instituto de Pesquisa Econômica Aplicada, Brasília, $160 \mathrm{p}$.

Matos, E. S. et al. (2016) "Sobre a trajetória de professoras negras na pós-graduação em Ciência da Computação: alguns resultados preliminares", In: Women in Information Technology (WIT 2016).

Nogueira, Oracy. Preconceito de Marca: as relações Raciais em Itapetininga. São Paulo: Editora da USP, 1998.

Nogueira, Oracy. Preconceito racial de marca e preconceito racial de origem: sugestão de um quadro de referência para a interpretação do material sobre as relações raciais no Brasil. Tempo Social Revista de Sociologia da USP, Editora da USP, v. 19, n. 1 p. 287-308. São Paulo, 2006.

Munanga, K. (2015) "Negritude: Usos e Sentidos”. 2a edição, Autentica, 96 p.

Mussalim, F. (2001) "Análise do discurso". In: Introdução à linguística: domínios e fronteiras, v. 2, n. 2, p. 101-142.

Pêcheux, M. (1995) "Semântica e discurso: uma crítica à afirmação do óbvio". Tradução Eni Puccinelli Orlandi, Campinas: Editora da UNICAMP.

PretaLAB. (2018). "Um levantamento sobre a necessidade e a pertinência de incluir mais mulheres negras na inovação e na tecnologia", In: PretaLAB, Equipe OLABI. Disponível em: https://www.pretalab.com/

Rago, M. (1985) "Do cabaré ao lar a utopia da cidade disciplinar. Brasil 1890-1930". Rio de Janeiro: Paz e Terra, 159 p.

Schiebinger, L. (2001) "O feminismo mudou a ciência”. Bauru: Edusc, 32 p.

Schwarcz, L. M. (1993). "O espetáculo das raças: cientistas, instituições e questão racial no Brasil”. São Paulo: Companhia das Letras, 99-133.

Skidmore, T. E. (1976) "Preto no branco: raça e nacionalidade no pensamento brasileiro". Rio de Janeiro: Paz e Terra, v.9.

Stepan, N. L. (2005) "A hora da eugenia: raça, gênero e nação na América Latina”. Rio de Janeiro: Editora Fiocruz. 